\title{
A Theoretical Study of Tropical Wave Disturbances
}

\author{
By M. A. Estoque and C. S. Cheng \\ University of Miami, Coral Gables, Florida, U.S.A. \\ (Manuscript received 9 April 1973, in revised form 15 October 1973)
}

\begin{abstract}
The properties of wave disturbances in the Trades are examined theoretically using a primitive equation model. The model is two-dimensional, nonlinear, and time-dependent. It incorporates the effects of condensation heating due to cumulus convection and nonconvective rain. Numerical integrations of the model show the development of two wave types. One wave type is a slowmoving synoptic disturbance while the other type is a fast-moving wave whose nature is not entirely understood. The structure, phase speed, and preferred wavelength of the waves are discussed. The integrations also show that condensation heating due to cumulus convection alone produces only extremely weak disturbances; condensation heating from nonconvective rain is necessary for the generation of large-amplitude disturbances.
\end{abstract}

\section{Introduction}

This report describes an attempt to deduce theoretically the properties of wave disturbances in the Trades. The properties are deduced from the numerical integrations of a nonlinear model. In order to provide some background for the theoretical work, we present a brief review of observational knowledge concerning the phenomenon.

The earliest studies of wave disturbances were done by Riehl (1954) for the Western Atlantic and by Palmer $(1951,1952)$ for the Pacific. Based on vertical time cross-section analyses of rawinsonde data, Riehl was able to deduce a fairly detailed picture of the vertical structure of the wave disturbances along the line of propagation. A complete three-dimensional structure, however, is still not available due to the lack of sufficient observations. But some attempts have been made by Yanai (1968), Estoque and Fernandez-Partagas (1973) and others towards the synthesis of the three-dimensional structure. Riehl's studies show that the waves move westward at the rate of about $6 \mathrm{~m} \mathrm{sec}^{-1}$; the average wavelength is approximately $2000 \mathrm{~km}$ and the period is 3 to 4 days. Organized upward motions together with rainy weather occur east of the troughline; fair weather and descending motions occur west of the troughline. The axis of the trough tilts eastward with height in the troposphere. The slope is very small in the lower troposphere, being practically vertical between the surface and 5,000 ft. At 20,000 ft. level, the trough axis lags behind the surface position by about 300 miles. The temperature distribution indicates that the disturbances are generally cold-cored; the largest negative temperature anomalies $\left(1\right.$ to $2^{\circ} \mathrm{C}$ ) occur in the lower troposphere in the trough or slightly to the east. The amplitude of the perturbation in the motion field is maximum near the 10,000 and the $40,000 \mathrm{ft}$. levels.

A more recent study of disturbances in the Pacific was made by Reed and Recker (1971) with the aid of a compositing technique. They found a similar, but not exactly the same structure as described above. Probably, the most significant difference is in the vertical motion field. Reed and Recker found that upward motions and rainfall occur directly over the trough instead of behind it. The area of rainfall is relatively extensive, covering large areas in front and behind the trough. There are also differences in the temperature structure. Whereas the negative temperature anomalies occur along the trough in Riehl's model, their studies indicate that they occur further to the east of the trough. It is not known whether these differences are real or whether they are due to the difference in the method of analysis. If they are real, they must be associated with geographical variations in the structure of the Trades.

The spectral analyses of radiosonde observations by Wallace and Chang (1969) and Nitta (1970, 1972) reveal the existence of at least five different 
wav etypes. The first type, the so-called YanaiMaruyama wave, travels westward with a speed of about 16 degrees of latitude per day. It has a wavelength of about $8,000 \mathrm{~km}$ and a period of 5 days. The amplitude of this wave is largest in the upper troposphere near the equator. It inclines strongly eastward with height below $150 \mathrm{mb}$ and westward above that level. The second type moves westward with a speed of about 5 degrees of latitude per day. It has a wavelength of about $2500 \mathrm{~km}$ and a period of about 5 days. This wave is detected in the lower troposphere and the latitude belt, $5^{\circ} \mathrm{N}$ to $10^{\circ} \mathrm{N}$. Its trough, which has no appreciable inclination with height, is a region of upward motions. The trough in the upper troposphere is the region of largest positive temperature anomalies; correspondingly, the ridge is characterized by relatively low temperatures. In the lower troposphere, the temperature perturbation indicates negative values halfway between the trough and the ridge. In structure, this wave resembles more closely that which was obtained by Reed and Recker than Riehl's classical easterly wave. The third wave is a westward moving wave (approximately $10^{\circ}$ of latitude per day) whose wavelength is about 10,000 $\mathrm{km}$. Its troughline inclines eastward in the troposphere. The axis of upward motion is almost vertical and is located approximately halfway between the trough and the ridge, closer to the ridge in the lower troposphere and closer to the trough in the stratosphere. The warm region lies roughly along the trough. The fourth wave type propagates westward at the rate of about $10^{\circ}$ of latitude per day; the wavelength is about $5,000 \mathrm{~km}$. Its amplitude is greatest in the upper troposphere at latitudes above $5^{\circ} \mathrm{N}$; it tilts slightly with height. Finally, the fifth type is the eastward moving Kelvin wave which has periods longer than 10 days and wavelength of about $11,000 \mathrm{~km}$. The wave amplitude is maximum at $150 \mathrm{mb}$.

The observational studies described above show large geographic variations in the wave properties which are presumably due to corresponding variations in the Trades. The effect of zonal variations in the Trades is clearly shown in the Atlantic which is relatively dry and stable in the eastern and moist and unstable in the western sections. During the summer, wave disturbances are observed to develop over Africa as small-amplitude, cold-cored systems. They travel westward (speed of about 7 degrees of latitude per day) across the Eastern and the Central Atlantic without significant changes in amplitude and structure. This approximate steady behavior is related to the dry and thermally stable conditions of the Trades in these regions. Upon arrival in the more unstable Western Atlantic, however, the disturbances oftentimes intensify, move more slowly and then become warm-cored.

In summary, our current observational knowledge concerning wave disturbances in the Trades indicate that large variations in wave structure, wavelength, and speed may occur. These variations are presumably associated with the existence of different wave types. Synoptic analyses indicate two major types - the small-amplitude cold-cored easterly wave and the high-amplitude warm-cored disturbance. On the other hand, spectral analysis reveal at least five different types, none of which correspond exactly to the types indicated by synoptic analyses.

A theoretical study of these waves has been made by Yamasaki (1969) using a two-dimensional quasi-geostrophic model. His model incorporates cumulus convective heating by assuming that the amount of latent heat released is proportional to the vertical velocity at the top of the friction layer. A stability analysis of the linearized equations show that four modes of unstable waves can occur. The occurrence of any of these modes depends on the vertical distribution of the cumulus convective heating with height and the vertical wind shear. The first mode, called tropical cyclone by Yamasaki, occurs if the convective heating is large in the lower troposphere and if the vertical wind shear is small. This is a warmcored disturbance whose growth rate increases with decreasing wavelength. If an appropriate horizontal diffusion coefficient is introduced (approximately $10^{7} \mathrm{~cm}^{2} \mathrm{sec}^{-1}$ ), the growth rate for the shortest wavelengths is sufficiently reduced so that the most unstable wavelength becomes of the order of a hundred kilometers. The second mode is an unstable wave which is due to the combined effect of convective heating and vertical wind shear. The preferred horizontal scale, ranging from 2,000 to $4,000 \mathrm{~km}$, increases with wind shear. The wave speed is approximately equal to the surface zonal velocity. The tilt of the trough with height is relatively small and the region of maximum rising motions is behind the trough, halfway between the trough and the ridge. The third mode is again an effect of convective heating 
and vertical wind shear, with preferred wavelengths between 2,000 and $4,000 \mathrm{~km}$ for reasonable values of wind shear. This mode differs from the second mode in three ways. First, its growth rate is maximum for moderate intensity of the shear. Second, this mode moves faster westward than the second mode. Third, its trough has a large tilt eastward with height in the troposphere, at least when the wavelength is small. It has been suggested by Yamasaki that the second and third modes correspond to easterly waves. The fourth mode occurs as a result of large heating by convection in the upper troposphere. The preferred scale of this wave depends on the vertical distribution of the heating; it ranges from 2,000 to $12,000 \mathrm{~km}$. Its trough has a large tilt with height in the troposphere. The amplitude of this wave is maximum in the upper troposphere. This mode and the third mode are simply unstable Rossby waves; hence, they move westward relative to the zonal flow.

A further study by Yamasaki (1971) using a three-dimensional primitive equation model confirms, in general, the findings from the aforementioned two-dimensional, quasi-geostrophic model. Although the behavior of wave disturbances deduced from these two models appear to have many realistic features, none of these waves have the cold-core feature in the lower and middle troposphere of Riehl's classical easterly wave. The cold core in Yamasaki's second and third modes are confined only to a thin layer in the low troposphere. It has been conjectured that this shortcoming may be eliminated by introducing a latitudinally varying basic current which is barotropically unstable. A recent study by Yamasaki and Wada (1972) appears to support, at least partially, this conjecture. They made a numerical stability analysis of a linear threedimensional quasi-geostrophic model. The undisturbed flow is a zonal easterly current whose speed is a function of both latitude and height. Its latitudinal variation is characterized by a jetlike maximum. They find that the basic flow is barotropically unstable even without cumulus convective heating and generates a cold-cored disturbance whose trough tilts eastward with height. However, the region of maximum ascending motions is located relatively close to the ridge axis. The incorporation of convective heating which is confined only to the upper troposphere results in a somewhat more realistic structure.
However, the region of ascending motions is still unrealistic because it is too far behind the trough, being halfway between the trough and ridge axis. Another unrealistic feature of the model disturbances is the tilt of the trough with latitude; it is eastward with latitude in the southern region but westward with latitude in the northern region. Observations show that the trough generally tilts eastward at all latitudes.

In summary, the theoretical studies show that different types of wave disturbances may be generated in the Trades. The wave properties vary from one type to another, depending upon particular instability mechanism (barotropic, baroclinic, and conditional instability of the second kind or CISK) which generates them. Since CISK alone could produce different wave types, one may conclude from the theoretical studies that a large number of wave types could occur in the Trades. However, observations show that only one type predominates. This is Riehl's cold-cored easterly wave which sometimes intensify into a warm-cored disturbance. It is fair to say that, at this stage none of the existing theoretical models has predicted satisfactorily that this be the case. This is due presumably to certain deficiencies in the models, such as the neglect of nonlinear effects and the inaccurate incorporation of temperature changes associated with condensation, evaporation and radiation. It will be noted that, in these models, the occurrence of condensation does not depend on the relative humidity of the prevailing flow.

Our present study is based on a model which attempts to eliminate some of the aforementioned deficiencies. The model is a two-dimensional, nonlinear, primitive equation model. It incorporates the following:

1) Nonlinear effects

2) Effects of the zonal variations in the basic flow

3) Parameterization of cumulus convective heating which depends on a varying moisture distribution

4) Heating released by large-scale or nonconvective rain

5) Cooling due to the evaporation of rain.

Numerical integrations of the model show that the CISK mechanism alone can generate only an extremely weak disturbance (maximum upward motions of a few $\mathrm{mm} / \mathrm{sec}$ ) in a standard tropical atmosphere. Strong disturbances develop only if 
the prevailing flow is sufficiently moist so that condensation heating by large-scale nonconvective rain becomes important. The structure of the disturbance resembles that described by Reed and Recker (1971).

\section{Dynamics of the model}

The model is a nonlinear, time dependent, primitive equation model; latitudinal variations of the motion field are ignored. A rectangular coordinate system with $x$ (east-west), $y$ (northsouth), and $z$ (vertical) as the space coordinates and $t$ as the time coordinate is used. The basic dependent variables are $u$ ( $x$ velocity component) $v$ (y velocity component), $w$ ( $z$ velocity component), $\theta$ (potential temperature), $p$ (pressure), and $q$ (specific humidity).

The horizontal equations of motion are

$$
\begin{aligned}
\frac{\partial u}{\partial t} & =-u \frac{\partial u}{\partial x}-w \frac{\partial u}{\partial z}+f v \\
& -\frac{1}{\rho} \frac{\partial p}{\partial x}-\frac{1}{\rho} \frac{\partial}{\partial z}\left(F_{u}\right)+K_{h} \frac{\partial^{2} u}{\partial x^{2}} \\
\frac{\partial v}{\partial t} & =-u \frac{\partial v}{\partial x}-w \frac{\partial v}{\partial z}-f u \\
& -\frac{1}{\rho} \frac{\partial p}{\partial y}-\frac{1}{\rho} \frac{\partial}{\partial z}\left(F_{v}\right)+K_{h} \frac{\partial^{2} v}{\partial x^{2}}
\end{aligned}
$$

Here, $\rho$ is assumed to be the density of the standard atmosphere. The last two terms of the above equations describe the effects of vertical and horizontal eddy diffusion.

The vorticity equation corresponding to these two equations is

$$
\begin{aligned}
\frac{\partial \xi}{\partial t} & =-u \frac{\partial \xi}{\partial x}-w \frac{\partial \xi}{\partial z}-\beta v-(f+\xi) \frac{\partial u}{\partial x} \\
& -\frac{\partial w}{\partial x} \frac{\partial v}{\partial z}-\frac{\partial}{\partial x}\left[\frac{1}{\rho} \frac{\partial}{\partial z}\left(F_{v}\right)\right]+K_{h} \frac{\partial^{2 \xi}}{\partial x^{2}}
\end{aligned}
$$

where $\xi \equiv \frac{\partial v}{\partial x}$. This equation replaces Eq. (2) as the prediction equation for $v$. The values of $v$ are obtained by integrating $\xi$ with respect to $x$ (from east to west), assuming $v=0$ at the eastern boundary.

The equation of motion along the vertical is assumed to be the hydrostatic equation

$$
\frac{\partial}{\partial z}\left(\frac{p}{p_{0}}\right)^{K}=\frac{g}{c_{p} \theta}
$$

The continuity equation for mass is

$$
\frac{\partial}{\partial x}(\rho u)+\frac{\partial}{\partial z}(\rho w)=0
$$

The other symbols are defined as follows: $f$, coriolis parameter; $\beta$, Rossby parameter; $\kappa=R / c_{p}$; $R$, specific gas constant for dry air; $c_{p}$, specific heat at constant pressure; $K_{h}$, horizontal eddy diffusion coefficient; $p_{0}=1000 \mathrm{mb} ; F_{u}$ and $F_{v}$ represent the vertical fluxes of momentum due to small scale eddy diffusion. The vertical fluxes are computed in the interior of the fluid using a constant eddy diffusion coefficient, $K_{z}=10^{5} \mathrm{~cm}^{2}$ $\mathrm{sec}^{-1}$. The horizontal eddy diffusion coefficient is assumed to be a constant equal to $10^{9} \mathrm{~cm}^{2} \mathrm{sec}^{-1}$. In the surface friction layer, the turbulent fluxes of momentum, heat, and moisture are computed using a drag coefficient such that

$$
F_{\alpha}=\rho C_{D} U_{2}\left(\alpha_{1}-\alpha_{2}\right)
$$

Here, $F_{\alpha}$ is the flux of any variable, $\alpha$, e.g. $u, C_{D}$ is the drag coefficient, and $U=\left(u^{2}+v^{2}\right)^{1 / 2}$. The subscripts, 1 and 2 , denote values at the surface $\left(z_{1}=0\right)$ and at some representative level $\left(z_{2}=10 \mathrm{~m}\right)$, respectively. The drag coefficient is set equal to $1 \times 10^{-3}$ everywhere except at a selected point $\left(20^{\circ}\right.$ of latitude away from the eastern boundary) where the value is $6 \times 10^{-3}$. The higher value at this point is used to initiate perturbations in the model by simulating the upslope and the downslope motions produced by flow over a mountain.

\section{Thermodynamic and moisture equations}

The moisture conservation equation for the model is

$$
\begin{aligned}
\frac{\partial q}{\partial t}+ & u \frac{\partial q}{\partial x}+w \frac{\partial q}{\partial z}=-\frac{1}{\rho} \frac{\partial}{\partial z}(F q) \\
& +K_{h} \frac{\partial^{2} q}{\partial x^{2}}+\left(\frac{\partial q}{\partial t}\right)_{c c}+\left(\frac{\partial q}{\partial t}\right)_{E}-\left(\frac{\partial q}{\partial t}\right)_{L R}
\end{aligned}
$$

Here, it is assumed that all condensation material falls out as rain. Vertical advection is neglected at the lowest gridpoint of prediction whenever cumulus convective transport occurs. There are five nonconservative processes corresponding to 
the five terms on the right hand side of the equation. The first and the second terms are analogous to the small-scale eddy diffusion terms for the momentum equations which have been described in the previous section and are computed in a similar way.

The term, $\left(\frac{\partial q}{\partial t}\right)_{c c}$ represents the effect of upward moisture transport by cumulus convection. This quantity is computed only when there is low-level moisture convergence in a conditionally unstable atmosphere. Its value is directly proportional to the low-level upward moisture flux and the saturation deficit of the environment. The formula for computing $\left(\frac{\partial q}{\partial t}\right)_{c c}$ will be presented in section 5 .

The term, $\left(\frac{\partial q}{\partial t}\right)_{E}$, represents the increase in water vapor due to the evaporation of rain in an unsaturated environment. The magnitude of this term is proportional to the saturation deficit of the environment and the amount of rain falling from upper levels. The formula for this term is presented in section 5 .

The term, $\left(\frac{\partial q}{\partial t}\right)_{L R}$, represents the effect of condensation due to large scale upward motion. This term is computed only when the air is saturated.

The prediction equation for potential temperature is

$$
\begin{aligned}
\frac{\partial \theta}{\partial t} & =-u \frac{\partial \theta}{\theta x}-w \frac{\partial \theta}{\partial z}-\frac{1}{\rho} \frac{\partial}{\partial z}\left(F_{\theta}\right) \\
& +K_{h} \frac{\partial^{2} \theta}{\partial x^{2}}+\left(\frac{\partial \theta}{\partial t}\right)_{c c}-\left(\frac{\partial \theta}{\partial t}\right)_{E} \\
& +\frac{\theta}{T} \frac{L}{c_{p}}\left(\frac{\partial q}{\partial t}\right)_{L R}-v \frac{\partial \theta}{\partial y}-R
\end{aligned}
$$

The first four terms on the right hand side describe the effects of advection and turbulent diffusion. Since these are analogous to terms in the momentum and moisture equations, no further elaboration is necessary. The term, $\left(\frac{\partial \theta}{\partial t}\right)_{c c}$, represents the release of latent heat due to cumulus convection. This quantity is computed only when there is low-level convergence in a conditionally unstable atmosphere. Its magnitude is proportional to the low-level upward moisture flux and to the relative humidity of the environment. The equation for computing, $\left(\frac{\partial \theta}{\partial t}\right)_{c c}$, is presented in section 5 .

The term, $\left(\frac{\partial \theta}{\partial t}\right)_{E}$, is the rate of cooling due to the evaporation of rain in unsaturated air. It is computed by using the expression

$$
\left(\frac{\partial \theta}{\partial t}\right)_{E}=\frac{L}{c_{p}} \frac{\theta}{T}\left(\frac{\partial q}{\partial t}\right)_{E}
$$

The term, $\frac{L}{c_{p}} \frac{\theta}{T}\left(\frac{\partial q}{\partial t}\right)_{L R}$, represents condensation heating associated with large-scale rain. It is computed only when the air is super-saturated.

The term, $\left(v \frac{\partial \theta}{\partial y}\right)$ is the meridional advection of potential temperature. The temperature gradient, $\frac{\partial \theta}{\partial y}$, is derived from the vertical wind shear with the aid of the thermal wind equation. Finally, the quantity, $R$, represents the effect of net radiational cooling. It is assumed to be equal to $1^{\circ} \mathrm{C}$ per day.

\section{Boundary conditions and the grid system}

In this section, we present the important boundary conditions for the model. At the lower boundary ( $z=0$, the earth's surface), the following conditions are prescribed:

$$
\begin{aligned}
& u=v=w=0 \\
& \theta=299.3^{\circ} \mathrm{K} \\
& q=q_{s}=22.8 \mathrm{~g} / \mathrm{kg}
\end{aligned}
$$

The upper boundary $(z=H)$ is a level which is sufficiently high so that one can assume that the vertical velocity is identically zero. The following conditions apply at $z=H$ :

$$
\begin{aligned}
& \begin{array}{l}
w=0 \\
\frac{\partial}{\partial z}\left(F_{u}\right)=\frac{\partial}{\partial z}\left(F_{v}\right)=\frac{\partial}{\partial z}\left(F_{\theta}\right)=\frac{\partial}{\partial z}\left(F_{q}\right)=0 \\
p=p_{H}(x, t)
\end{array}
\end{aligned}
$$

The expression for computing $p_{H}(x, t)$ is derived from the equation of continuity, the east-west equation of motion, and the hydrostatic equation. The derivation is indicated below. 
Averaging the continuity equation with respect to height in the interval $z=0$ to $H$ and using the boundary conditions for $w$, one gets

$$
\frac{\partial}{\partial x}(\overline{\rho u})=0
$$

where the overbar denotes a vertical average. We assume that the integral of the above equation is

$$
\overline{\rho u}=\text { pure constant }
$$

Substituting this in the vertically-averaged $u$ momentum equation, one obtains

$$
\frac{\partial \bar{p}}{\partial x}=-\overline{\rho G}
$$

where

$$
\begin{aligned}
G \equiv & -u \frac{\partial u}{\partial x}-w \frac{\partial u}{\partial z}-f v \\
& +\frac{1}{\rho} \frac{\partial}{\partial z}\left(\rho K_{z} \frac{\partial u}{\partial z}\right)+K_{h} \frac{\partial^{2} u}{\partial x^{2}}
\end{aligned}
$$

By definition,

$$
\bar{p} \equiv \frac{1}{H} \int_{0}^{H} p d z
$$

The variable, $p$, is obtained from the hydrostatic equation as

$$
p=\left[\left(p_{H}\right)^{\kappa}+\frac{g}{c_{p}}\left(p_{0}\right)^{\kappa} \int_{z}^{H} \frac{d z}{\theta}\right]^{1 / k}
$$

Since $\bar{p}$ in Eq. (7) can be obtained from Eq. (6), one can consider Eqs. (7) and (8) a set of simultaneous equations in $p_{H}$ and $p$. This set is solved by a method of successive approximations.

Lateral boundary conditions for the prediction equations are required only at inflow points. At these boundaries. the horizontal gradients of the wind, potential temperature, and moisture are assumed to be zero. In order to obtain $v$, we integrated the equation, $\frac{\partial v}{\partial x}=\xi$.

The prediction equations are integrated numerically using a forward time, upstream space differencing scheme. It may be noted that this scheme introduces an artificial viscosity which depends upon the time and space increments as well as the wind speed. For the choice of increments in our integrations, the artificial

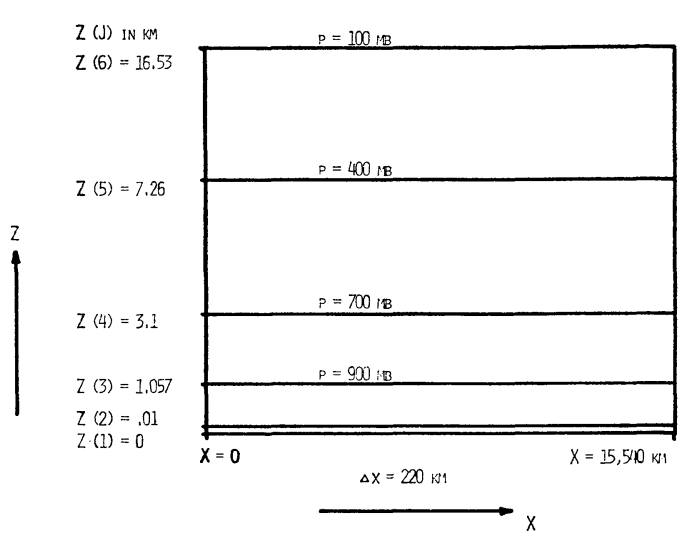

Fig. 1. The coordinate and the grid system.

viscosity is generally of the same order of magnitude as that given by the assumed value of the model eddy viscosity except in regions of low wind speeds. The domain of computation and the grid are shown in Fig. 1. There are six grid points along the vertical; the spacing is variable. All variables are defined at these grid points. Along the east-west direction, there are seventy grid points which are equally spaced $\left(\Delta x=2^{\circ}\right.$ latitude). The time step, $\Delta t$, is equal to 30 minutes.

\section{Condensation and evaporation effects}

Nonadiabatic heating due to condensation and cooling by evaporation of rain are important processes in tropical wave disturbances. Therefore, it is essential for any realistic model to incorporate these processes accurately. In this section, we present a detailed description of how these processes are incorporated.

It is assumed that condensation heating is due to cumulus convective rainfall in a conditionally unstable atmosphere and to large-scale rainfall in a saturated environment. The amount of cumulus convective rainfall is assumed to be directly proportioned to two factors; the intensity of low-level upward moisture flux and the relative humidity of the large-scale flow. The first factor is a common feature of existing methods of parameterizing cumulus convective heating while the second factor is generally not included. It is clear, however, that the relative humidity is an important factor. For observations definitely show that greater amounts of cumulus rain tend to occur in moist environments. On the other hand, cumulus clouds tend to evaporate and to produce little rain when the relative humidity of the environment is low. In order to incorporate 
these two factors, we parameterized cumulus convective heating by combining the ideas of Estoque (1968) and Yamasaki (1968). Convective heating is computed at two levels corresponding to the fourth $\left(z_{4}=3.1 \mathrm{~km}\right)$ and the fifth $\left(z_{5}=7.25\right)$ grid points. The following formulas are used:

At $z=z_{4}$ :

$$
\begin{aligned}
& \left(\frac{\partial \theta}{\partial t}\right)_{c c}=\left(\frac{\theta}{T}\right)_{4}\left(\frac{L}{c_{p}}\right) \frac{(R H)_{4} l F^{*} q}{\rho_{4}\left(z_{5}-z_{4}\right)} \\
& \left(\frac{\partial q}{\partial t}\right)_{c c}=\frac{(1-R H)_{4} l F^{*} q}{\rho_{4}\left(z_{5}-z_{4}\right)}
\end{aligned}
$$

At $z=z_{5}$ :

$$
\begin{aligned}
& \left(\frac{\partial \theta}{\partial t}\right)_{c c}=\left(\frac{\theta}{T}\right)_{5}\left(\frac{L}{c_{p}}\right) \frac{R H_{5}(1-l) F *_{q}}{\rho_{5}\left(z_{6}-z_{5}\right)} \\
& \left(\frac{\partial q}{\partial t}\right)_{c c}=\frac{(1-R H)_{5}(1-l) F *_{q}}{\rho_{5}\left(z_{6}-z_{5}\right)}
\end{aligned}
$$

where $F^{*}=(\rho w)_{3} \frac{q_{2}+q_{3}}{2}$ for upward motion

$$
=0 \text { for downward motion }
$$

Here, $\mathrm{RH}$ is the relative humidity. The parameter, $l$, determines the partition of the total cumulus convective heating between levels $z_{4}$ and $z_{5}$. The expression for $l$ below has been suggested originally by Yamasaki (1968).

$$
l \equiv \frac{\left(\theta_{c}\right)_{4}-\theta_{4}}{\left(\theta_{c}\right)_{4}-\theta_{4}+\left(\theta_{c}\right)_{5}-\theta_{5}}
$$

Here, $\theta_{c}$ is the potential temperature of the undiluted ascending thermal. This temperature is based on the moist adiabat of the saturated air at the surface and is computed empirically with the following formulas:

$$
\begin{aligned}
& \left(\theta_{c}\right)_{5}=57.8+2.3\left(\theta_{s}-20\right)+273.2 \\
& \left(\theta_{c}\right)_{4}=36.9+1.3\left(\theta_{s}-20\right)+273.2 \\
& \theta_{s}=27.0+0.04\left(1000-p_{s}\right)
\end{aligned}
$$

where $\theta_{s}$ is the surface potential temperature in ${ }^{\circ} \mathrm{C}$ and $p_{s}$ is the surface pressure in mbs.

The condensation heating due to large-scale rainfall, $\frac{L}{c_{p}} \frac{\theta}{T}\left(\frac{\partial q}{\partial t}\right)_{L R}$ is obtained with the aid of a simplified method for computing the largescale rainfall rate, $\left(\frac{\partial q}{\partial t}\right)_{L R}$. This is done by examining whether the air is supersaturated. If it is, then the rate is computed by using the formula

$$
\left(\frac{\partial q}{\partial t}\right)_{L R}=\frac{q-q_{s}}{\Delta t}
$$

where $\Delta t$ is the time step of integration. It will be noted that this formula will tend to overestimate the amount of water condensed and, hence, the condensation heating.

The cooling by evaporation at any level, $z(J)$, is obtained by approximating the evaporation rate empirically. The formula, which is based on a formula used by Kessler (1969) is:

$$
\begin{aligned}
\left(\frac{\partial q}{\partial t}\right)_{E} & =1.93 \times 10^{-6}\left(10^{7}\right)^{0.35} \\
& \left(q_{s}-q\right)_{J}\left[\rho_{J+1}\left(q-q_{s}\right)_{J+1} \times 10^{6}\right]^{0.63}
\end{aligned}
$$

This quantity is computed only when the air is supersaturated at $z(J+1)$ and unsaturated at $z(J)$. Hence, the equation indicates that rain at an upper level is allowed to fall and to evaporate at a lower level. The use of the above formula tends to overestimate the evaporation. In order to minimize this tendency, the total amount of water condensed for each time step is not allowed to exceed the saturation deficit.

\section{Design of the numerical experiments}

The integrations have been made in order to determine the effect of certain factors in the development of the disturbances. The factors are wind shear, variation of the coriolis parameter, horizontal variations in the moisture and condensation heating due to cumulus convective as well as large-scale rain. The characteristics of the disturbances are also examined in relation to these factors. Some of the questions which we would like to answer with the aid of our numerical integrations are:

(1) Which of the two instability mechanisms, CISK or baroclinic, generate disturbances? Is condensation heating due to large-scale rainfall important in the development of the disturbances? What is the role of orographically-induced upslope motions in generating disturbances? Is the variation of the coriolis parameter an important factor in the development of the disturbances? How fast do the disturbances intensify?

(2) What are the phase speeds and the wavelengths of the disturbances? 
Table 1. Chacteristics of the numerical experiments

\begin{tabular}{|c|c|c|c|c|}
\hline Expt. No. & Wind $\left(\mathrm{m} \mathrm{sec}^{-1}\right)$ & $\beta\left(\mathrm{cm}^{-1} \mathrm{sec}^{-1}\right)$ & Moisture Field & Heating \\
\hline 1 (Control) & -6 & $2.2 \times 10^{-13}$ & horizontally uniform & conv. and nonconv. \\
\hline 2 & -6 & 0 & , & conv. and nonconv. \\
\hline 3 & $U \alpha p$ & $2.2 \times 10^{-13}$ & ," & conv. and nonconv. \\
\hline 4 & -6 & ", & dry east, moist west & conv. and nonconv. \\
\hline 5 & , & , & horizontally uniform & convective \\
\hline 6 & ," & ", & $"$, & nonconv. \\
\hline
\end{tabular}

(3) What are the space $(x-z)$ distributions of wind, vertical motion, temperature, and moisture associated with the disturbances? How do the trough lines tilt with height? How is the kinetic energy of the disturbances maintained?

In order to answer these questions, we made six separate integrations or experiments of the model. Each experiment differs from another one with respect to the basic flow properties (wind or moisture), condensation heating, or value of the Rossby parameter $(\beta)$. The difference in the basic flow from one experiment to another is incorporated by an appropriate change in the initial conditions. Table 1 summarizes the characteristics of each experiment.

The first of these experiments is designated as the Control Experiment because it differs from any of the rest in only one aspect. By comparing any particular experiment with the Control Experiment, one may isolate the effect of one factor. The integrations for all the experiments were carried out for a period of about ten days of meteorological time and for latitude $10^{\circ} \mathrm{N}$.

\section{The control experiment}

The initial conditions for this experiment consist of a current which is easterly $\left(u=-6 \mathrm{~m} \mathrm{sec}^{-1}\right.$, $v=w=0$ ) and whose temperature and moisture vary only with height as shown in Fig. 2. The temperature profile is essentially that of the standard tropical atmosphere; the moisture distribution is slightly more moist than the standard tropical atmosphere at upper levels. Starting with these initial distributions, we integrated the model for a period of 10 days of real time. Fig. 3 shows the time evolution of some of the zonally averaged properties of the flow. The upper part of the diagram shows the time variations of the potential temperature and the relative humidity at the $400 \mathrm{mb}$ level. It may be seen that the temperature initially decreases with time,

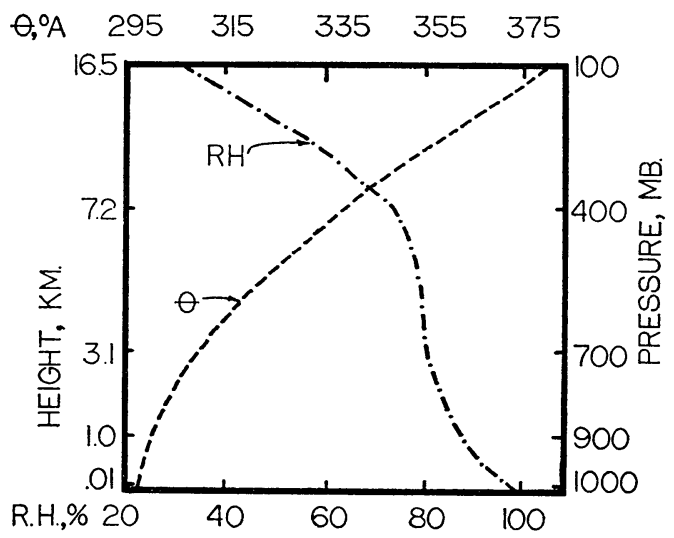

Fig. 2. The initial conditions for potential temperature and relative humidity.

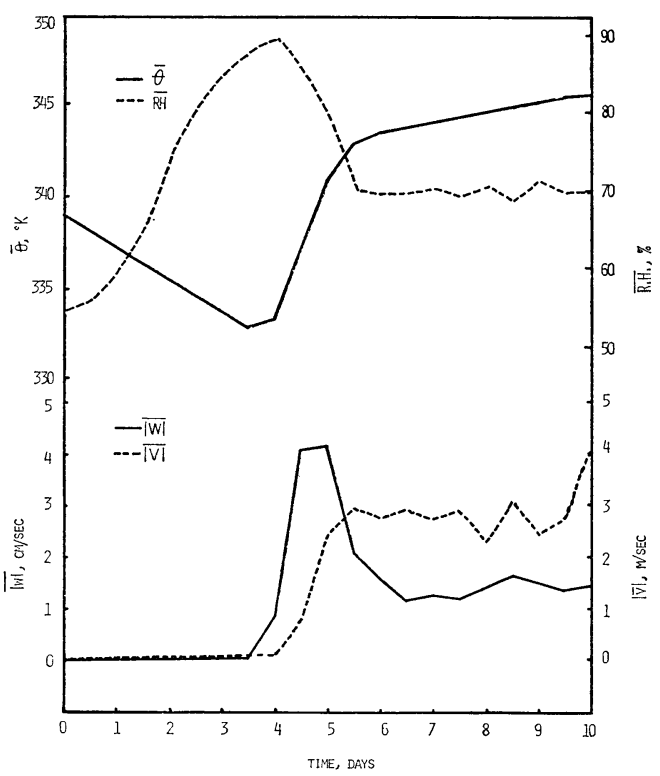

Fig. 3. The time evolution of the zonally averaged values at the $7.2-\mathrm{km}$ level of potential temperature, relative humidity, absolute value of vertical velocity $(|W|)$, and absolute value of the meridional velocity $(|v|)$. 


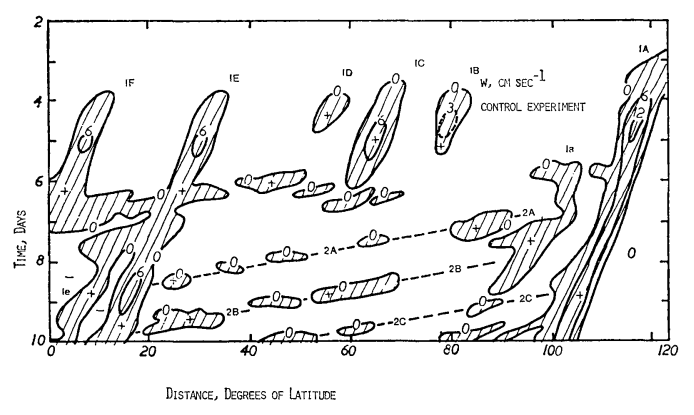

Fig. 4. The time evolution of the vertical velocity at the $3 \mathrm{~km}$ level for the Control Experiment.

reaching a minimum at 3 days. The decrease is the effect primarily of radiational cooling and, to a small extent, of vertical mixing. After reaching the minimum, the temperature increases rapidly at first and then less rapidly. The increase in temperature is due to the release of the latent heat of condensation. The corresponding zonally averaged relative humidity at the same level is almost a mirror image of the temperature curve; a maximum is reached at about 3 days, corresponding to the temperature minimum. This variation indicates that the relative humidity changes are primarily due to the temperature changes. The lower portion of the diagram shows the degree to which the basic current is perturbed. Here we have plotted two measures of the average intensity of the perturbations - the zonally-averaged vertical and meridional velocity components. Note the rapid development of perturbations during the fourth day. This is due to the instability of the basic flow which occurs at about 4 days when the relative humidity has become sufficiently high to allow a high rate of condensation heating. The results of Experiments 5 and 6 indicate that condensation heating during the early stage of wave development is due to the large-scale or nonconvective instead of cumulus convection rain. Some general features of the disturbances appear in Fig. 4 which shows an $x-t$ diagram of the vertical velocity at the $700 \mathrm{mb}$ level. Two wave types may be recognized. Disturbances under the first wave type are indicated as $1 \mathrm{~A}, 1 \mathrm{~B}, 1 \mathrm{C}, 1 \mathrm{D}, 1 \mathrm{E}$, and $1 \mathrm{~F}$. These are slowmoving, high amplitude synoptic waves. The wave speed is about $4 \mathrm{~m} \mathrm{sec}^{-1}$, which is approximately equal to the average wind at the 700-mb level as shown in Fig. 5. At the initial

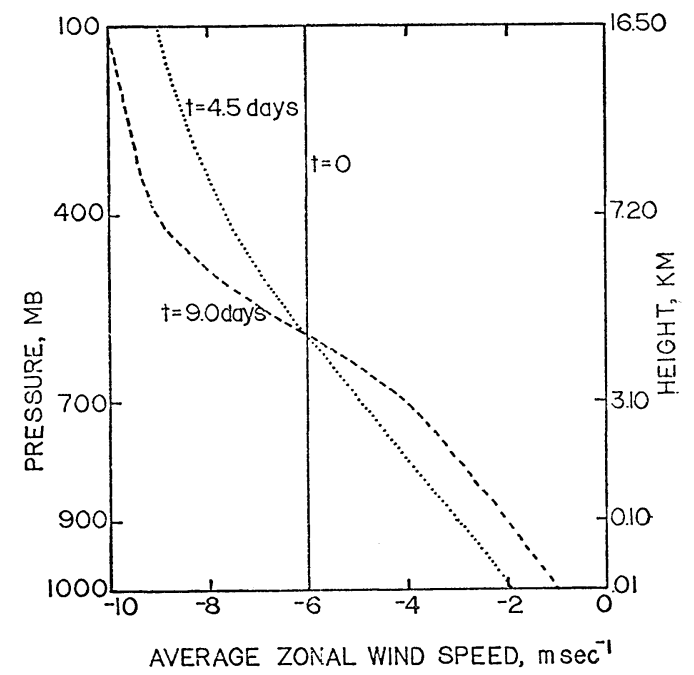

Fig. 5. The zonally averaged east-west wind component at $t=0,4.5$, and 9 days for the Control Experiment.

stages the preferred wavelength is approximately $3000 \mathrm{~km}$; however, this wavelength subsequently increases, becoming approximately $9000 \mathrm{~km}$ after the sixth day.

The increase in the preferred wavelength with time during the period, $t=4$ to 10 days, is probably related to the corresponding changes in the static stability and the relative humidity of the basic flow. Fig. 3 indicates that, during this period, the static stability increases while the relative humidity decreases. The first disturbance which develops, Wave $1 \mathrm{~A}$, is generated by the surface upslope motion which is induced by the increased roughness at the point, $x=120$. Other disturbances grow subsequently downstream. An interesting feature of the wave train is the secondary region of upward motion (labelled as la) which appears to be generated by $1 \mathrm{~A}$. A similar region, le, forms ahead of Wave $1 \mathrm{E}$.

Further details concerning the wind, temperature and moisture of the Type 1 waves are shown in Figs. 6 to 11; the figures show the vertical $(x-z)$ cross-sections at $t=4.5$ days and $t=9$ days. Figs. 5 to 7 show the structure during the time of maximum development. The tropospheric troughs, which appear to have very little tilt with height, are regions of upward motions. Overlying the lower tropospheric trough are regions of higher mixing ratios and temperatures. The higher mixing ratios are due to vertical advection while 


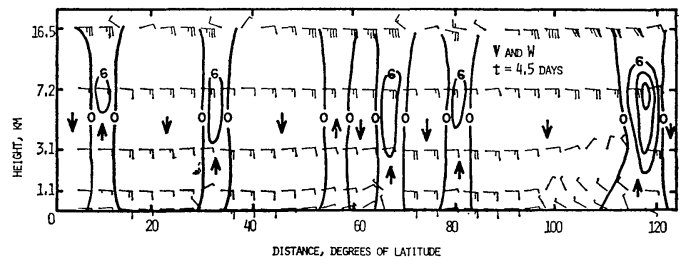

Fig. 6. The vertical cross-section of the horizontal wind $(\bar{V})$ and the vertical velocity at $t=4.5$ days for the Control Experiment. Units: full barb $=5 \mathrm{~m} \mathrm{sec},{ }^{-1}$, flag, $25 \mathrm{~m}$ $\mathrm{sec}^{-1}$; vertical velocity, $\mathrm{cm} \mathrm{sec}{ }^{-1}$.

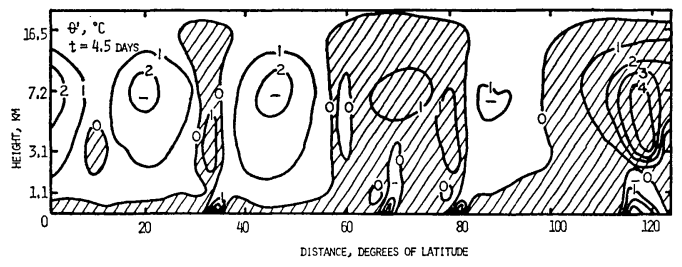

Fig. 7. The vertical cross-section of potential temperature deviation from the zonal average at $t=4.5$ days for the Control Experiment. Shaded areas are warm regions.

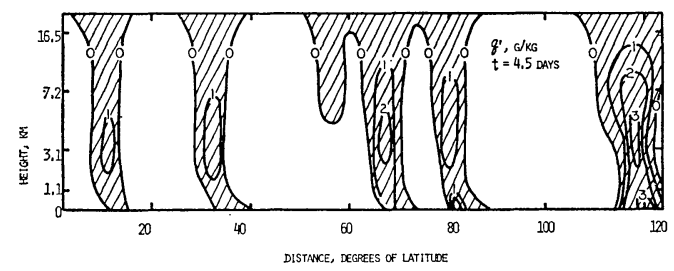

Fig. 8. The vertical cross-section of specific humidity deviation from the zonal average at $t=4.5$ days for the Control Experiment. Shaded areas are moist regions.

the higher temperatures are due to heat released by condensation. The trough tends to be cold in the lower tropospheric layers; this tendency is due to cooling by the evaporation of rain. Lower temperatures also tend to occur behind the trough at upper levels. Behind the trough in the low troposphere, the easterlies are strong; in the stratosphere directly above these easterlies, the wind tends to become westerlies. This wind distribution is associated with the convergence at low levels and divergence at upper levels. The amplitude of the velocity perturbation is largest in the stratosphere where density is small. The corresponding cross-sections at $t=9$ days are shown in Figs. 9 to 11 ; this is a period when the disturbances are in a mature stage. In general,

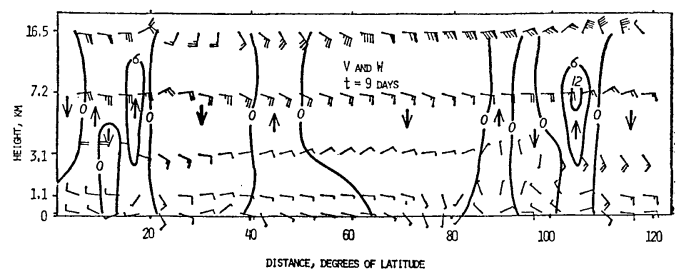

Fig. 9. The vertical cross-section of the horizontal wind $(\bar{V})$ and the vertical velocity at $t=9$ days for the Control Experiment. Units: full barb $=5 \mathrm{~m} \mathrm{sec}^{-1}$, flag, $25 \mathrm{~m}$ $\mathrm{sec}^{-1}$; vertical velocity, $\mathrm{cm} \mathrm{sec}^{-1}$.

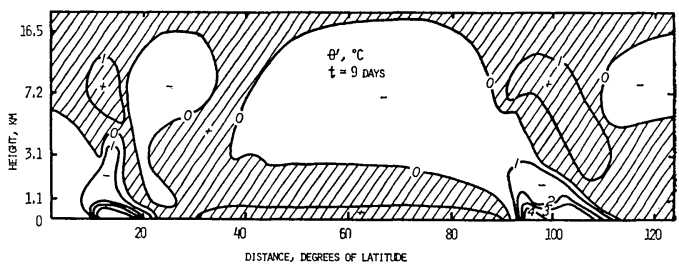

Fig. 10. The vertical cross-section of potential temperature deviation from the zonal average at $t=9$ days for the Control Experiment. Shaded areas are warm regions.

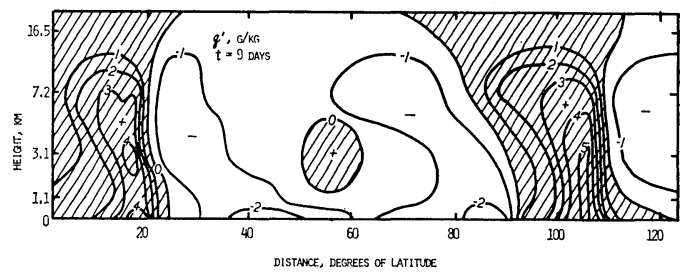

Fig. 11. The vertical cross-section of specific humidity deviation from the zonal average at $t=9$ days for the Control Experiment. Shaded areas are moist regions.

the structure at this time is similar to that for $t=4.5$ days. On the basis of the wave characteristics just presented, one may conclude that the Type 1 wave resembles more the composite disturbance described by Reed and Recker rather than Riehl's easterly wave.

The second wave type which is generated by the model is exemplified by the waves indicated by $2 \mathrm{~A}, 2 \mathrm{~B}$, and $2 \mathrm{C}$ (Fig. 4). These are fast moving, low amplitude waves. The wave speed is about $45 \mathrm{~m} \mathrm{sec}^{-1}$ and the wavelength is about $5000 \mathrm{~km}$. The nature of this wave cannot be identified clearly from the numerical integrations. Since its phase speed is very much larger than the average zonal wind speed, it is probably a gravity wave. 


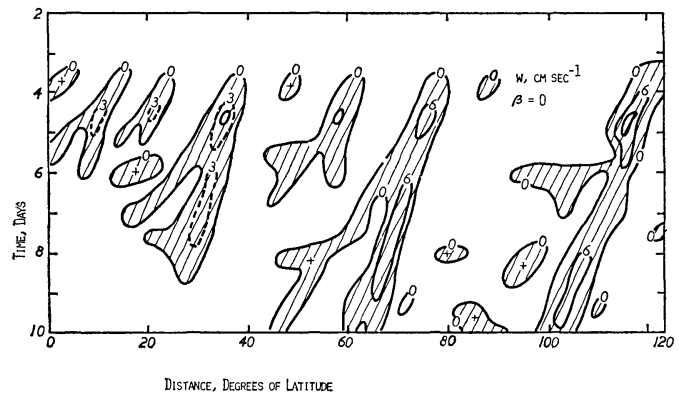

Fig. 12. The time evolution of the vertical velocity at the $3 \mathrm{~km}$ level for Experiment 2 .

\section{Results of other experiments}

This section discusses the effects of different factors in the occurrence and the behavior of the disturbances. This is done by comparing the results of the other experiments with those of the Control Experiment.

Experiment No. 2 has been designed to determine the role of the latitudinal variation of the coriolis parameter, $\beta$, in the development of disturbances. This experiment is exactly the same as the Control Experiment except for the fact that $\beta$ was set equal to zero; Rossby waves are, therefore, eliminated. Fig. 12 shows the $x-t$ diagram for the vertical velocity. This diagram should be compared to Fig. 4 which is the corresponding diagram for the Control Experiment. It will be seen that, inspite of the fact that $\beta$ is equal to zero, disturbances (Wave Type 1) still develop. This result appears to indicate that the disturbances in the Control Experiment are not unstable Rossby waves. It is seen also that the preferred wavelength for this experiment is less than that of the Control Experiment. Thus, at time $t=7$ days, the wavelength is $4000 \mathrm{~km}$, which is about one half of the preferred wavelength in the Control Experiment. Hence, the $\beta$ effect appears to increase the wavelength.

Experiment 3 was intended to determine the effect of vertical wind shear or baroclinicity. This is done by replacing the initially constant wind in the Control Experiment with one which varies linearly with pressure. The initial wind is $10 \mathrm{~m} \mathrm{sec}^{-1}$ from the east at the surface, decreasing to zero at the top $(p=100 \mathrm{mb})$. Fig. 13 shows the $x-t$ diagram for the vertical velocity. It may be seen that wave development in the early stages is essentially the same as in the Control Experiment. However, at the later stages, the wavelength

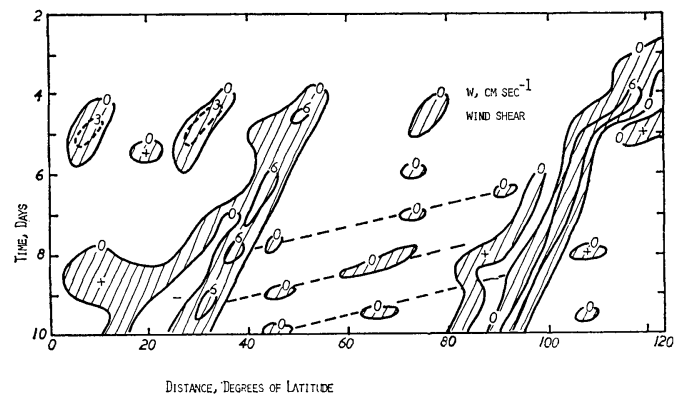

Fig. 13. The time evolution of the vertical velocity at the $3 \mathrm{~km}$ level for Experiment 3 .

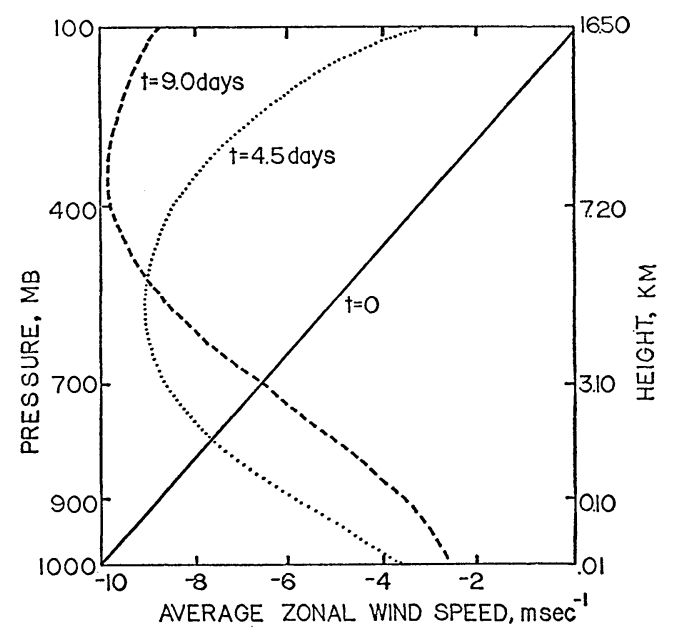

Fig. 14. The zonally averaged east-west wind component at $t=0,4.5$ and 9 days for Experiment 3 .

is smaller than that of the Control Experiment. For example, the wavelength at $t=10$ days for this experiment is about $6000 \mathrm{~km}$ while that of the Control Experiment is $9000 \mathrm{~km}$. While the shorter wavelength must be indirectly related to the initial linear wind profile, it is probably more appropriate to interpret it as an effect of the jet-like wind profile shown in Fig. 14 which prevails during the period of development. This diagram shows the zonally averaged wind at $t=0, t=4.5$ days, and $t=9$ days. Note that the initial wind profile is modified rapidly with time so that, during the period of wave development, the basic flow is no longer linear with pressure.

We have noted earlier that high moisture content is a favorable factor in the development of disturbances. This factor is explored in Experiment 4 which simulates the effect of a horizontally nonuniform moisture distribution in the basic 
flow. The simulation is done by making a numerical integration which is the same as the Control Experiment except for the initial moisture distribution. The initial moisture distribution for Experiment No. 4 is characterized by a dry eastern portion and a moist western portion, resembling roughly conditions over the major oceans. The initial relative humidity for the western portion $(0<x<90)$ is the same as that of the Control Experiment. In the eastern portion $(90<x<140)$, we made the relative humidities smaller. The actual values are: $65 \%$ at $1000 \mathrm{mb}$, $50 \%$ at $900 \mathrm{mb}, 40 \%$ at $700 \mathrm{mb}, 30 \%$ at $400 \mathrm{mb}$ and $20 \%$ at $100 \mathrm{mb}$. The principal characteristics of the Experiment No. 4 integration are shown in Fig. 15 which shows the $x-t$ diagram of the vertical velocity at the $700-\mathrm{mb}$ level. This should be compared with the corresponding diagram for the Control Experiment, Fig. 4. Note that the only significant disturbance develops in the moist region. This is a Type 1 wave. In the dry eastern region, only small-amplitude Type 2 disturbances develop.

The last two experiments (Experiment 5 and 6) examine the relative importance of convective rain and nonconvective or large scale rain as condensation heat sources for wave disturbances. Experiment No. 5 is designed to determine the effect of condensation heating due to convective rain. This experiment is exactly the same as the Control Experiment except for the fact that condensation heating due to nonconvective rain has been set to zero. The results of the integrations for this experiment showed the development of disturbances with a preferred wavelength of about $4000 \mathrm{~km}$. However, their amplitudes are extremely small. At the time of maximum

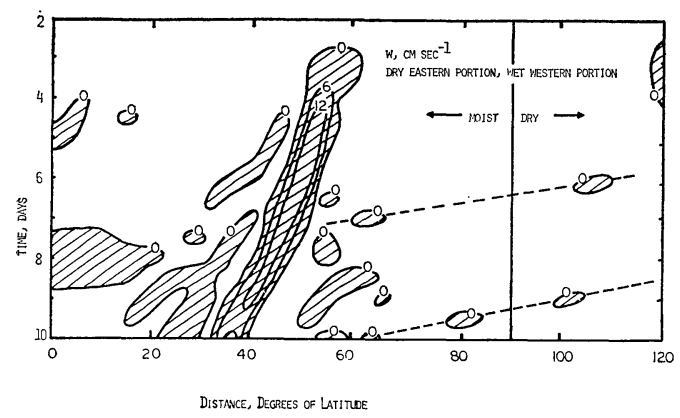

Fig. 15. The time evolution of the vertical velocity at the $3 \mathrm{~km}$ level for Experiment 4. intensity ( $t=4$ days), the largest value of the vertical velocity is $0.2 \mathrm{~cm} \mathrm{sec}^{-1}$. On the basis of this experiment, one can conclude that convective heating alone could not generate disturbances with appreciable amplitudes. This conclusion is rather surprising, for some previous theoretical studies have attempted to explain disturbances in the Trades as solely the effect of cumulus convective heating. The discrepancy between previous studies and our study may be due to differences in the manner of parameterizing cumulus convective heating. In these previous studies all of the upward flux of moisture due to low-level convergence is assumed to be condensed into rain. In our study, however, only a portion of it (proportional to the ambient relative humidity) becomes rain. The remaining portion is not used in producing rain and, hence, do not contribute to heating; it is used to increase the water vapor of the environmental air.

Experiment No. 6 is the same as the Control Experiment except for the fact that the condensation heating due to cumulus convection was eliminated. Hence, the only source of condensation heating in Experiment 6 is the large-scale rainfall. This experiment produced synoptic scale disturbances whose amplitudes are large, although slightly smaller than those of the Control Experiment. The smaller amplitudes are not surprising because cumulus convective heating, which is an additional energy source, has been eliminated.

Fig. 16 provides a convenient comparison of the amplitudes and the wavelengths of the

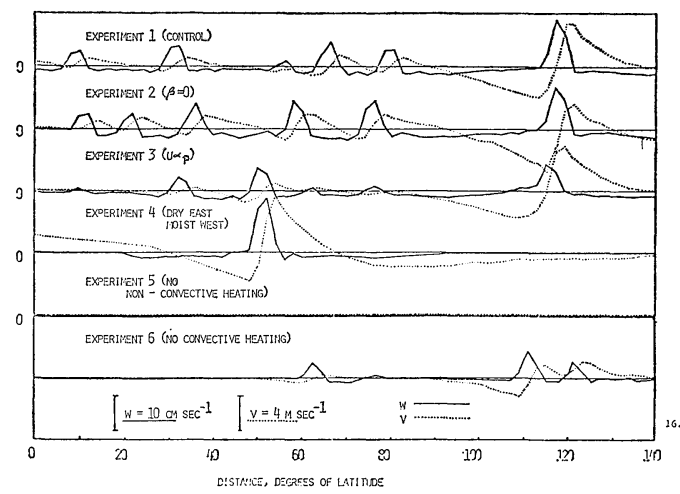

Fig. 16. East-west profiles of vertical velocity and meridional wind component at the $900-\mathrm{mb}$ level, $t=4.5$ days, for all experiments. 
disturbances for all the experiments. This diagram shows the east-west profiles of the vertical velocity and the meridional wind component at the $900-\mathrm{mb}$ level and for $t=4.5$ days.

\section{Summary and conclusion}

The properties of disturbances which develop in a basic easterly flow resembling the Trades have been examined using a two-dimensional primitive equation model. The nonadiabatic heat sources for the model are condensation heating by cumulus convection and by nonconvective or large-scale rain. The heat sinks are cooling by radiation and evaporation of rain. Cumulus convective heating is assumed to be proportional to the low-level convergence and to the relative humidity of the large-scale flow. The initial perturbations in the model are triggered by a surface roughness inhomogeneity near the upwind eastern boundary. Numerical integrations of the model equations show the development of two wave types. The first type is a high-amplitude synoptic scale disturbance while the second type appears to be a small amplitude gravity wave.

The synoptic disturbances are instabilities in the basic flow which are initiated by an upstream surface inhomogeneity. The major energy source for the developing wave is the release of latent heat by large scale rainfall. Cumulus convective heating appears to be only a minor energy source during the early stages of development; however, it becomes more important as the amplitude of the wave increases. The minor role of cumulus convective heating in the growth of the disturbance is entirely unexpected. This finding is in disagreement with previous theories which show that CISK is a mechanism for the generation of waves in the Trades.

There are several possible interpretations of this disagreement. First, we can make the assumption that CISK is, indeed, a mechanism for the generation of the waves. Then, the lack of wave development in our model when heat is released only by cumulus convection is due to the fact that it is too viscous; the large viscosity damps out the growing disturbances. This lack of wave development may be explained also by the fact that our model has underestimated the heating due to cumulus convection. It is entirely possible that the nonconconvective heating in our model would be reflected as cumulus convective heating if a more realistic cumulus parameterization were introduced.

Second, we can make the assumption that CISK is not a mechanism for the generation of waves. Therefore, previous theories which explain waves. as a result of CISK are erroneous. The most probable source of error in these theories is that they have overestimated the magnitude of the heating by cumulus convective heating and, consequently, the growth rate of the unstable waves. If the assumption in this paragraph is correct, then we must look for alternative mechanisms to explain wave generation in the Trades. An alternative mechanism which has been suggested previously (Nitta and Yanai, 1969) is barotropic instability.

\section{Acknowledgements}

The research was supported by the Atmospheric Sciences Section, National Science Foundation, NSF Grant GA-31645.

\section{References}

Estoque, M. A., 1968: Vertical mixing due to penetrative convection. J. Atmos. Sci., 25, 1046-1051.

, and J. Fernandez-Partagas, 1973: On the structure of a tropical weather system. (To be published in Bonner Meteorologische Abhandlungen, Vol. 17).

Kessler, E., 1969: On the distribution and continuity of water substance in atmospheric circulation. Meteor. Mongor., 10, No. 32, 84 pp.

Nitta, T. and M. Yanai, 1969: A note on the barotropic instability of the tropical easterly current. J. Meteor. Soc. Japan, 47, 127-130.

Nitta, T., 1970: Statistical study of tropospheric wave disturbances in the tropical Pacific region. $J$. Meteor. Soc. Japan, 48, 47-60.

- 1972: Structure of wave disturbances over the Marshall Islands during the years of 1956 and 1958. J. Meteor. Soc. Japan, 50, 85-103.

Palmer, C. E., 1951: Tropical Meteorology. Compendium of Meteorology, Boston, Amer. Meteor. Soc., 859880.

1952: Tropical meteorology. Quart. J. Roy. Meteor. Soc., 78, 126-164.

Reed, R. J. and E. E. Recker, 1971: Structure and properties of synoptic-scale wave disturbances in the equatorial western Pacific. J. Atmos. Sci., 28, 1117-1133.

Riehl, H., 1954: Tropical Meteorology. New York, McGraw-Hill, 392 pp.

Wallace, J. M. and C. P. Chang, 1969: Spectrum analysis of large scale wave disturbances in the tropical lower troposphere. J. Atmos. Sci., 26, 1010-1025. 
Yamasaki, M., 1968: A tropical cyclone model with parameterized vertical partition of released latent heat. J. Meteor. Soc. Japan, 46, 202-214.

1969: Large-scale disturbances in a conditionally unstable atmosphere in low latitudes. Papers in Meteor. and Geophys., 20, 289-336. 1971: A further study of wave disturbances in the conditionally unstable model tropics.
J. Meteor. Soc. Japan, 49, 391-415. and M. Wada, 1972: Vertical structure of the barotropically unstable wave in a tropical easterly current. J. Meteor. Soc. Japan, 50, 271284.

Yanai, M., 1968: Evolution of a tropical disturbance in the Caribbean Sea region. J. Meteor. Soc. Japan, 46, 86-108.

\title{
熱帯波動擾乱の理 論的研 究
}

\author{
M. A. Estoque and C. S. Cheng \\ マイアミ大学, フロリダ, アメリカ
}

熱帯貿易風帯中の波動擾乱の性質をプリミティブモデルを用いて理論的に調べた。モデルは 2 次元, 非線型で, か つ時間変動のモデルである. 積雲対流及び非対流性の雨に伴う凝結熱の効果をとり入れている. 数值積分の結果によ れば，2つのタイプの波が発達し，ひとつはゆっくり移動するシノプティックな擾乱で他は速く移動する波である. 後者の波の性質についてはよくわからない，これらの波の構造，位相速度，卓越波長について論じた，また，積分結 果によれば, 積雲対流による凝結熱だけでは非常に弱い擾乱しか生じない，大きな振幅をもった擾乱ができるために は非対流性の雨からの凝結熱が必要である。 